\title{
HOW TAX COMPLEXITY AND ENFORCEMENT AFFECT THE EQUITY AND EFFICIENCY OF \\ THE INCOME TAX
}

\author{
Louis Kaplow
}

Working Paper 5391

\author{
NATIONAL BUREAU OF ECONOMIC RESEARCH \\ 1050 Massachusetts Avenue \\ Cambridge, MA 02138 \\ December 1995
}

This paper is part of NBER's research program in Public Economics. Any opinions expressed are those of the author and not those of the National Bureau of Economic Research.

(C) 1995 by Louis Kaplow. All rights reserved. Short sections of text, not to exceed two paragraphs, may be quoted without explicit permission provided that full credit, including (C) notice, is given to the source. 


\title{
HOW TAX COMPLEXITY AND ENFORCEMENT AFFECT THE EQUITY AND EFFICIENCY OF THE INCOME TAX
}

\begin{abstract}
Much criticism of the income tax involves administration: the enormous complexity of the system is responsible for large compliance costs, public and private, and the tax gap is large despite substantial resources devoted to enforcement. The desire for simplification and improved compliance motivates various incremental reforms as well as proposals for fundamental restructuring of the tax system. But evaluation of such changes is difficult because the underlying problems have not been analyzed in terms of the equity and efficiency concerns that animate more familiar assessments of income tax policy. This article provides a framework for a unified analysis, in which the same factors that are used to justify the choice of the tax base and the rate structure are employed to resolve problems involving complexity, compliance costs, and enforcement difficulties.
\end{abstract}

Louis Kaplow

Harvard Law School

HFB 322

Harvard University

Cambridge, MA 02138

and NBER 


\section{INTRODUCTION}

Is an income tax preferable to a consumption tax? Which fringe benefits should be included in the tax base? What capitalization rules should apply to exploration costs or research and development under an income tax? These and countless other questions have long been studied from the perspective of ideal tax policy, which is concerned about the equity (distributive effects) and efficiency of the tax system.

Recently, analysts have paid increasing attention to the rather significant details of implementation. Complex tax systems impose large compliance costs, which Slemrod (1995) suggests are on the order of $\$ 75$ billion for the U.S. income tax. And taxes are not self-enforcing: the GAO (1995) estimates the 1992 tax gap for the U.S. income tax to be $\$ 110$ to $\$ 127$ billion.

The magnitude of these problems of complexity and enforcement commands attention and, it would seem to many, demands action. Moreover, the significance of compliance costs and enforcement difficulties warrants rethinking basic questions of tax design: perhaps tax rules or even tax systems that are desirable in principle should be redesigned in practice, sacrificing the original equity and efficiency goals to some extent for the sake of improving tax administration.

An obstacle to analysis of complexity and enforcement is the lack of an obvious common denominator. If, for example, eliminating a set of deductions would reduce compliance costs at the expense of the equity or efficiency of the tax system, how is one to decide whether the change is warranted? More broadly, if the compliance cost of an income tax is $\$ 100$ billion and that of a national sales tax or V.A.T. would be half as high, how does one decide whether the savings justifies the cost with regard to distributive objectives? Or, with regard to enforcement, if raising the IRS budget $\$ 5$ billion would close the tax gap by $\$ 25$ billion, is the expenditure sensible in 
light of the alternative of increasing tax rates sufficiently to raise the same revenue without incurring the additional enforcement costs? Of what relevance is the fact that some taxpayers currently pay $100 \%$ of what they owe while others pay but a small fraction of their tax obligations?

The present article presents a conceptual framework for addressing these questions. It begins by outlining the standard method by which economists integrate the analysis of distributive objectives and efficiency. Then, this method is applied to contexts that involve typical problems of complexity and enforcement. In each instance, both the equity and efficiency implications will be identified, and it will be suggested how this framework is capable of incorporating the relevant factors in a unified analysis.

The conclusion is that a common denominator can be found, making it possible to provide more structure and coherence to policy analysis involving complexity, enforcement, and other problems of tax administration. The analysis, nonetheless, is not easy. It is necessary to state one's distributive objectives clearly and to obtain empirical evidence concerning the behavioral effects and incidence of tax reforms that affect the complexity of the tax system or the enforcement of tax rules. It is hoped that the present investigation, by defining the questions more precisely, will guide future work so that information on the most relevant questions will become increasingly available.

\section{INTEGRATING DISTRIBUTIVE OBJECTIVES AND EFFICIENCY}

When engaging in normative analysis of complex problems, economists begin by stating an objective function, often called a social welfare function. Conventionally, this function indicates how social welfare depends upon individuals' well-being, referred to as individuals' utility. Individuals' utility will depend how individuals are affected by the relevant policy variables. 
To be more specific, an individual's utility (U) might be expressed as a (positive) function of his consumption (C) and a (negative) function of his labor effort (L). Thus, a utility function may be written as

$$
U(C, L) .
$$

The individual is assumed to choose a level of labor effort to maximize his utility. Taxes are relevant because they affect how much labor income the individual is permitted to use for consumption. ${ }^{1}$ Using this formulation, the analyst can determine the effect of various tax regimes on how much an individual works and thus how much income will be available for consumption. (In order to make this determination, the analyst must specify the utility function, indicating precisely the manner and extent to which the individual values additional consumption and disfavors additional labor effort. In addition, one would designate the tax schemes to be studied.) Then, given the results concerning labor effort and consumption, the analyst can compute the individual's utility level.

Once this process has been completed for a population of individuals (who may have different utility functions and face different wages), a tax scheme can be evaluated using some social welfare function. Two common social welfare functions are the utilitarian one -- the summation of individuals" utilities -- and the so-called "maximin" welfare function -- which directs that the well-being of the worst-off individual (the one with the minimum level of utility) be maximized, without regard to the effects on others. To illustrate, the utilitarian social welfare function (W) can be expressed as

$$
W=\sum_{i=1}^{n} U_{i},
$$


where there are $n$ individuals and $U_{i}$ is the utility function of individual $i$. This utilitarian welfare function (like others that are usually studied) tends to favor equality, other things equal. The reason is that individuals' utility is believed to exhibit decreasing marginal utility of consumption - that is, an additional dollar is worth less to those who already have more. As a consequence, social welfare would rise if the tax system redistributed a dollar from a rich individual to a poor one. Complete equality is not, however, the optimal outcome due to the incentive effects of taxation and redistribution. Thus, there is the familiar trade-off between redistribution and incentives. A social welfare function consists, essentially, of a precise statement of how much weight should be given to the gains and losses of various individuals that arise under a designated regime.

The primary tax policy application of this method appears in the literature on the "optimal income tax." The question addressed in this literature is how redistributive the income tax should be in light of its adverse effect on incentives. The output of the analysis indicates how much revenue should be raised to fund transfers and the shape of the optimal income tax schedule (i.e., whether marginal tax rates increase, at what rate, and so on). The input to the analysis has three dimensions. First, the analyst must specify the social welfare function. Second, the analyst must supply information on individuals' utility functions, such as data on the rate at which individuals trade off leisure and consumption and on the extent to which individuals value a marginal dollar more when they are poor than when they are rich. ${ }^{2}$ Third, the analyst must employ additional data about the economy, notably concerning the distribution of skills in the population and the wages associated with different skills. Given such specifications and information, it is possible to determine what tax schedule is optimal.

The procedure just described is daunting: controversial value judgments are required in 
specifying the welfare function, empirical judgments must be made despite much uncertainty, and the analysis itself is challenging. But there really is no other choice. How can one expect to make coherent statements about the appropriate degree of redistribution without making explicit value judgments and offering predictions about how behavior will be affected by the tax system?

To illustrate, suppose that careful analysis demonstrated that under existing circumstances a highly egalitarian social welfare function would be maximized by a tax system under which the marginal (but not average) tax rates on the rich would be lower than those on other individuals. (The suggestion is not hypothetical, as many analyses have suggested this possibility: reducing the marginal rate on the rich may induce enough additional work effort at a small enough direct revenue cost to allow an improvement in total welfare.) A political progressive might attack the implicit policy recommendation as reactionary. But such an attack would be nonsensical. If the analysis has been performed correctly, the seemingly conservative position is truly what the egalitarian should favor. The progressive critic is merely confused, not understanding the subtle

relationship between his value judgments (ends) and how different policies (means) might bear on them.

Return now to the problems of tax administration, of complexity and enforcement. The questions posed in the introduction might seem intractable, not susceptible to being reduced to a common denominator. My claim is that the framework just described, which has been employed successfully to analyze the problem of the optimal extent and form of redistribution, can be used to illuminate the problems of complexity and enforcement.

\section{COMPLEXITY AND COMPLIANCE COSTS}

\section{Statement of the Issue}

A tax system may be complex and thus involve greater compliance costs for many reasons 
and in many ways. For present purposes, I shall focus on one important source of compliance costs: those arising from the need to make the tax base more accurately reflect taxpayers' relative taxpaying ability. Additional compliance costs may arise on account of more complex rules, for example, rules that attempt to distinguish more precisely between deductible business expenses and nondeductible personal expenses, or rules that include a range of fringe benefits in income. As another example, if imputed income from housing and other sources were to be taxed, greater compliance costs would be incurred.

It should be emphasized that the immediate costs of complexity cannot be measured by looking solely at the rules themselves. The primary source of compliance cost involves taxpayers' behavior, often involving record-keeping, so estimates of incremental paperwork costs are usually more probative than counts of the number of pages of rules. ${ }^{3}$ Similarly, the difficulty of an audit will usually depend upon problems of verifying the details of taxpayer behavior rather than challenges of understanding the rules themselves. Indeed, more precise rules might reduce ambiguity, easing compliance costs, or might close avenues for complicated avoidance schemes.

The very use of an income tax (or personal consumption tax) rather than a sales tax or a head tax involves the use of a substantial and complex set of rules imposing significant compliance costs on taxpayers and administrators for the purpose of assessing each taxpayer's circumstances more accurately in terms of some notion of their equitable tax burden. Thus, even fundamental tax reforms can be analyzed as an instance of changing (greatly) the degree of complexity, raising the trade-off between compliance costs and accuracy of assessment.

Many other dimensions of complexity will not be addressed directly in this investigation. Some complexity arises from poor rule-writing, which involves a pure waste. Other complexity arises from rules that consciously deviate from tax principles in order to subsidize certain activities 
and groups (R\&D, farmers, homeowners). In this case, it is easy to say that the rules should be eliminated, if they are viewed as inequitable, inefficient, and complex, their existence being attributed to special interest politics or past mistakes. In such instances, the complexity problem is merely the tail. On the other hand, if one is to take the objective of the special provisions as desirable -- serving a legitimate purpose that is usefully carried out through the tax system -- one could apply the present analysis. The benchmark for equitable treatment may change and behavioral effects that otherwise might be deemed inefficient (diverting resources from industrial capacity to housing) might now be viewed as efficient.

\section{Equity Effect}

The spirit of the analysis can be captured in a simple example. Suppose that two individuals each have a true income of $\$ 40,000$. However, unless a special deduction is provided (for a type of pure business expense), one of the individuals will have reported income of $\$ 45,000$. The simple scheme, without the deduction, overtaxes this individual. (If the marginal tax rate is $20 \%$, she pays $\$ 1000$ too much.) The more complex scheme, with the deduction, taxes both individuals equally, but involves additional costs (record-keeping for the deduction, greater audit expenses to prevent fraudulant deductions). ${ }^{4}$

Consider also the following variation: under the simple scheme, both individuals have reported income of $\$ 40,000$; but one has true income of $\$ 45,000$ due to an in-kind fringe benefit. A more complex scheme -- dealing with valuation and enforcement difficulties -that taxed the fringe benefit would properly measure the true income of both. A simple scheme undertaxes one individual. This variation will be skipped in the discussion to follow; the analysis is the same, just reversing the directions of the effects.

To focus on the equity effect, suppose for the moment that behavior is fixed; that is, suppose that individuals' earnings and the extent of the business expenses governed by the rule are unaffected by deductibility. Then the simple scheme, which allows no deduction, has the 
equity cost of mis-taxing one of the individuals. Assuming that levying the tax on true income produces the correct level of tax, social welfare will be lower on this account.

What, exactly, is the welfare cost of this loss in equity? The overtaxed individual, by definition, pays too great a relative share of the total tax burden. (She pays $\$ 1000$ more than otherwise identical taxpayers.) One must look to the social welfare function, which contains the distributive preferences to compute how much welfare is lower. To explain, the social welfare function indicates how welfare is affected as a function of each individual's situation. One would expect the social welfare function to place some weight on equalizing income. ${ }^{5}$ The extent of that weight and other factors (notably, incentive effects) is what presumably determined the tax rate structure initially. The same social preferences are relevant in assessing the equity cost of overtaxing the individual with $\$ 40,000$ in true income but $\$ 45,000$ in taxable income under the simple system. ${ }^{6}$

To be concrete, for a given specification of the social welfare function and other parameters (such as individuals' trade-off between income and leisure), one could simply compute social welfare for the case in which this erroneous specification is made. One could then, for example, compute how much government revenue would have to be "destroyed" in the case with no error in income measurement to produce the same figure for social welfare. This revenue measure -- suppose it is $\$ 200$ in the present example -- could be taken as a measure of the benefit of proper income measurement in the present context.

The compliance cost can now be factored in directly. Suppose, for example, that all the additional compliance costs of the more complex, accurate regime are borne by the government. If this cost is less than $\$ 200$, the more complex rule would increase social welfare; if the cost is less than $\$ 200$, the additional complexity would be socially excessive. 
More realistically, some (much) of the additional compliance cost will borne by the taxpayer (record-keeping, more complex instructions) and only a portion by the government (writing rules, more complex and costly auditing). The portion borne by the taxpayer -- unlike when she paid too much tax -- is both an equity cost (in that she still pays, now through compliance costs, a bit more than she ideally should) and an efficiency cost (in that the added amount she pays involves a waste of resources in addition to the increase in the government's expenditures). To evaluate this situation, the analyst would compute social welfare given the actual situation that would confront the affected taxpayers and taking into account the administrative cost borne by the government. This level of social welfare would then be compared to that in the absence of the complex rule, with the resulting mismeasurement of income.

In sum, it is possible to translate compliance costs into conventional efficiency costs. It is also necessary to take into account distributive effects, primarily because it is the distribution problem that motivates expending resources to improve the accuracy of income measurement. The same social preferences that dictate the nature and extent of redistribution have direct implications for the welfare cost of inequity arising when individuals' burdens deviate from the ideal.

\section{Comments on the Equity Analysis}

One might object that the purposed analysis of complexity and compliance costs requires one to invoke an agreed-upon social welfare function, which is unavoidably controversial given the value judgments involved. But this need for choosing a welfare function should not be viewed as a problem with the framework. Rather, it is virtue because such value judgments must be made and articulated if one is to measure equity costs in a manner that will allow one to say whether it 
is worth a given level of real resource costs to eliminate the inequity. As suggested previously, inequity is costly only because we care about how much tax various individuals pay; that is, we care about distributive justice. We employ redistributive taxes. ${ }^{7}$ In doing so, a decision is made to redistribute from the rich to the poor (and from the upper-middle class to the lower-middle class, and so on). Implicit in this decision is some notion of what it means to be rich and poor (suggesting some tax base) and a judgment of the weight attached to any given redistribution. One could develop views on these matters in two ways - through reflection and analysis or by inferring the value judgments of our society from the nature and extent of redistribution currently undertaken. Either way, some conclusion is necessary before the analysis can proceed. (Alternatively, an analyst might present results for a range of distributive norms, allowing the reader to supply a value judgment and, accordingly, identify the applicable results.) Policy recommendations that eschew this step merely hide value judgments; they cannot avoid them.

It should be useful to offer further comments about the quantification of the equity effect, short of sending someone to the computer to reassess social welfare for every incremental reform (although this is becoming rather cheap and easy these days). One obvious point is that, the higher the marginal tax rate, the more important any tax base mismeasurement will be. Another is that mismeasurement is likely to have a more significant effect on social welfare in the case of lower-income individuals. (The equity cost of taxing an individual with true income of $\$ 5,000$ by $\$ 1,000$ too much is substantially greater than a $\$ 1,000$ mistake for an individual whose true income is $\left.\$ 40,000 .^{8}\right)$ Looking at the income tax in isolation, these effects seem to run in opposite directions because higher-income individuals are in higher tax brackets. If one integrates transfer programs, however, the result is quite different. Due to welfare phase-outs and tax phase-outs (EITC, child care credits, IRA's), the poor and other lower-income individuals often have very 
high de facto marginal tax rates. In that case, the equity cost of mismeasurement is unambiguously greater per dollar of error for those with lower income. (Perhaps this explains why welfare eligibility rules are often more complex than tax rules, using shorter accounting periods, measuring assets, and including additional sources of income.)

To some readers, the equity problem analyzed here may seem like one often discussed under the rubric of "horizontal inequity," which refers to the unequal treatment of equals. Observe, however, that no special horizontal equity definition or measure was needed. The social welfare function is already taken to embody social preferences concerning the distributive share each citizen should pay. The problem is that the identified taxpayer pays relatively too much, compared to the ideal. If there were no other taxpayer with true income of $\$ 40,000--$ and thus no unequal treatment of "equals" -- this would still be a problem, and essentially to the same extent. Similarly, if the mismeasurement applied to each of a large number if taxpayers with $\$ 40,000$ of true income (but not those with higher or lower true income), the problem would be magnified, not eliminated. ${ }^{9}$

Because the problem involves mismeasurement of a sort that reduces the degree of distributive justice in a manner already captured by the very social welfare function used to determine the tax base and rate structure, it follows that measurement of the inequity must be derived from the social welfare function itself rather than from various ad hoc equity indexes that sometimes have been proposed. This does not imply, however, that pragmatic shortcuts are unavailable. For example, analysts could examine hypothetical reforms involving, say, a $\$ 1,000$ overpayment of tax by individuals with true income of $\$ 10,000, \$ 50,000$, and $\$ 100,000$, with the social welfare costs expressed in terms of the government administrative cost that would produce indifference. (Recall the above example, in which the "cost" of the mismeasurement for a 
$\$ 40,000$ individual was $\$ 200$.) One could then produce simple charts that could be used for ruleof-thumb guidance in deciding on hosts of details. At a minimum, the suggested approach would provide ballpark estimates that would clearly resolve many questions, given the necessary data. Presumably, many reforms would not be close questions, although given that there has really been no welfare analysis of this sort to date we have little idea which reforms they would be.

The present formulation also tells us in what form we need data in order to assess reforms that affect compliance costs and tax equity. Primarily, we need to know the extent of mismeasurements by income, so that we can apply the proper weights. (Note that if mismeasurements are large for some individuals but not others, an average mismeasurement, even by income class, would not suffice.) In addition, the incremental compliance costs attributable to a more accurate regime must be estimated and their incidence determined, for if they are borne by the affected taxpayers any equity benefit from the more costly provision will be incompletely realized. ${ }^{10}$

\section{Efficiency Effect}

The equity analysis assumed that behavior was independent of the tax treatment. If one is talking, say, about whether to have a special provision for the blind, this assumption would be correct. (That is, providing tax breaks for the blind would be unlikely to have a significant effect on how many individuals were blind. ") But usually one would expect a behavioral response. If in-kind fringe benefits are not taxed, more such benefits will be provided. If a legitimate business expense is not deductible (because allowing it would be more complex), one would expect there to be less spent on that activity. Also, to the extent that the business expense was sector-specific (say, it involved only the fishing industry), that sector would then face higher costs, charge higher

prices, and thereby contract somewhat. Similarly, some fringe benefits (tax-free flights for airline 
employees) will benefit particular industries by lowering their after-tax costs, leading to some expansion.

In the limit, such behavioral responses might totally drive out any inequity. ${ }^{12}$ To simplify our discussion, assume that this is the case. (The case of partial behavioral response involves simply a combination of each of the two extremes. ${ }^{13}$ ) When the behavioral response is complete, the preceding equity analysis can be ignored. Workers denied the deduction will be overtaxed, but in long-run equilibrium their before-tax income must be higher, so that their after-tax income is the same as in the case in which the deduction is permitted. The difference, now, is that there will be less production in the affected sector and a bit more in other sectors because of the effect of denying the deduction on labor costs. The resulting distortion in the allocation of resources will tend to be inefficient, reducing social welfare.

This distortion is equivalent to the familiar one arising from differential taxation. For example, special depreciation rules and other tax expenditures have been criticized because they cause interindustry distortion or, within industries, distortions in the mix of inputs. These familiar efficiency problems arise when the tax system intentionally discriminates. In the present context, the discrimination is incidental, in that it results because implementing the desired rule would be administratively costly. But the effect on efficiency is precisely the same. As a consequence, the efficiency cost can be analyzed in the usual way: one measures the resulting price differences, estimates elasticities, and determines the deadweight loss due to the distortion.

To complete the welfare analysis, this deadweight loss from the distortion would be compared with the administrative cost of implementing the tax provision that avoids the initial mismeasurement. ${ }^{14}$ As noted, if the behavioral response is complete, the analysis would consist entirely of this simple efficiency comparison, without the need to assess the previously discussed 
equity effect.

Accuracy in Administration

The previous discussion emphasized "complexity" -- i.e., the detail or precision of rules and regulations with regard to differentiating behavior (or preventing spurious differentiation, such as by including in-kind fringe benefits in income) and the resulting compliance costs imposed on taxpayers. Although the discussion thus far speaks in terms of the applicable rules, one can also speak of the accuracy with which particular rules are administered.

To illustrate, suppose that miscellaneous employee business expenses are deductible, but that similar personal expenses are not. Now, compare a gentle audit strategy and an intensive, more accurate one. (Both the probability of audit and the care with which audits are performed are relevant here, the latter having received little attention in the academic literature.) Under the gentle strategy, many mistakes will be overlooked. Moreover, taxpayers will be inclined to be aggressive, leading to systematically excessive deductions. The opportunity for such excessive deductions will vary among taxpayers (some occupations more lend themselves to attempting additional deductions without creating the appearance of obvious fraud; taxpayers will differ in their knowledge of the opportunity and their temperament with regard to compliance). As a result, the sorts of inequities and inefficiencies identified with simple, imprecise rules will arise. By contrast, an intensive strategy will correct more mistakes and, more importantly, induce taxpayers to be less aggressive in the first place. But this strategy will be more costly. ${ }^{15}$

In sum, the equity and efficiency analysis of the accuracy of tax administration is quite similar in structure to that of complexity and compliance costs. One can simply view loose administration and enforcement as a de facto simple regime whereas with tight administration the rule that is more complex on the books will have a the previously hypothesized effect of a 
complex rule in practice. (Put yet another way, the analysis of complex rules simply assumed that they would be enforced to a substantial extent.) This suggests that the analysis of many issues concerning the administration and enforcement of rules is quite similar to the analysis used to assess the rules themselves. The section to follow, which focuses directly on tax enforcement, will reinforce this view.

\section{ENFORCEMENT}

There are many tools of tax enforcement -- information-reporting requirements, audits (which may vary in probability, intensity, and selection criteria), and sting operations, among others -- and a range of penalties that might be utilized. Moreover, different forms of noncompliance -- failing to report cash income, excessive deductions, complex business manipulations, as of transfer pricing -- raise diverse problems. In each context and with respect to each tool, the questions presented in the introduction might be asked: by what criteria is one to determine whether enforcement expenditures are cost-justified, in an absolute sense or by comparison to raising revenue by raising tax rates, and what is the relevance of the fact that the degree of compliance varies among taxpayers? This section provides a framework for answering these questions -- one that, it turns out, is remarkably similar to that presented in the previous section addressed to complexity and compliance costs.

\section{The Problem}

For concreteness, I will focus on one of the most important sources of noncompliance for individual taxpayers, underreported labor income. The GAO (1995) indicates that the selfemployed report only 36 percent of their income and "informal suppliers" report just 11 percent of their income (compared with 97 percent compliance by wage earners), and unreported income by sole proprietors alone constitutes more than a quarter of the estimated tax gap (with other 
unreported income contributing more than another quarter). ${ }^{16}$

More precisely, suppose there are two types of workers, employees who work for large enterprises and inevitably receive accurate W-2's indicating their true labor income, and selfemployed individuals in businesses in which cash is a significant portion of gross receipts. The former have little choice but to comply, whereas the latter have significant opportunity to evade.

Now consider a proposed enforcement plan that, at a nontrivial cost, would make a significant dent in this noncompliance problem. It may involve a higher audit rate, more intensive audits when they are undertaken, greater information reporting by purchasers (e.g., in sectors where there are large businesses who are buyers), or elaborate sting operations involving undercover agents. All that matters for present purposes is that there exists a strategy that would have a real effect, but at a serious enough cost that it is not obvious whether it is desirable. Should the additional enforcement be undertaken?

In the academic literature, it is well understood (although not always remembered or emphasized) that the proper cost-benefit analysis does not simply compare the enforcement cost to the revenue raised. ${ }^{17}$ Why this extremely common approach (exemplified by the heavy emphasis at hearings and in the press on revenue raised per dollar of IRS budget) is misguided can be seen in a number of ways. One is to note that enforcement costs involve the use of real resources, whereas tax receipts involve transfers. (To be sure, the government "deserves" the money and needs it, but it remains the case that uncollected taxes are not lost resources.)

Another way to look at the problem is to consider alternatives. The government can raise revenue by a slight rate increase or an addition to the enforcement budget. ${ }^{18}$ Select the rate increase that raises the same revenue as the proposed enforcement program. The rate increase does not consume real resources the way greater enforcement expenditures do, so on efficiency 
grounds it might appear that the rate increase is preferable. (Rate increases are not politically popular; but nor, it turns out, are a larger IRS budget, wider information reporting requirements, and so on.) Greater enforcement, however, may have more positive equity and efficiency effects, as will now be described. ${ }^{19}$

Analysis

Return to the original example, in which one type of worker pays all the tax owed and the other type is able to evade substantially. In order to meet a stated revenue requirement, a higher tax rate will be required. ${ }^{20}$ In the end, employees pay significantly more taxes on the same income than do the self-employed.

As in the discussion of complexity and compliance costs, assume first that there is no behavioral effect. In that case, there is an equity cost. Some individuals pay relatively too much tax; others pay relatively too little. This equity cost is precisely the sort analyzed in the previous section and can be measured in the same manner. In place of administrative and compliance costs, one now has enforcement costs, which are analogous. Thus, assessing whether the equity cost of evasion warrants greater enforcement (instead of simply raising tax rates) involves the same sort of cost-benefit analysis as was suggested when determining whether greater complexity to provide more accurate tax treatment justified the additional compliance costs. One can compute the effect of mismeasuring relative income on social welfare and determine the welfare cost in terms of an equivalent amount of government revenue. If this cost is greater than the enforcement cost required to eliminate the problem, greater enforcement will raise social welfare.

Now suppose, more realistically, that there is a behavioral effect. To this extent, instead of an equity cost there will be an efficiency cost. In particular, consider individuals of a given skill level who are deciding whether to be an employee in sector A or entrepreneur in sector B. For 
given work effort and resulting income, the employee in sector A pays much higher taxes. This will encourage individuals to be entrepreneurs in sector $B$. When the labor market is in long-run equilibrium, the following will be true. First, the net, after-tax wages of the two sets of workers must be such that their utilities are the same. If that is the case, there is no equity effect. (It may appear that there is an equity effect -- those in A pay taxes on all of their income and those in B do not. But those in A receive, in equilibrium, a higher before-tax wage to compensate for this difference in taxation; those in B have depressed earnings because of the additional flow of workers into B as a result of the tax differential.) Second, the tax difference causes an economic distortion: the economy has too much labor in sector B and too little in sector $\mathrm{A}$.

Like the equity cost, this efficiency cost is entirely familiar. It is the same distortion that would have resulted with perfect enforcement but different tax rates in the two sectors. That is, the effect of imperfect enforcement in this instance is, de facto, a higher tax rate in sector $A$ than in sector B. This produces the familiar intersectoral distortion. ${ }^{21}$ Moreover, it is the same sort of distortion discussed in the case of rules that were not sufficiently complex to avoid imposing different real tax burdens on individuals with similar true incomes. Thus, to assess the efficiency cost, one would again measure the elasticities, use that information to quantify the deadweight loss, and proceed to determine whether the additional expenditure on enforcement was sufficiently low to be cost-justified. To indicate the potential significance of this problem, consider Alm's (1985) estimate of an aggregate distortion in excess of $\$ 100$ billion from tax evasion that involves resources flowing into the underground economy.

When enforcement is imperfect, the efficiency problem is not limited to the distortions just described; there are additional inefficiencies because taxpayers expend resources directly on noncompliance. (One may operate less efficiently in order to have more funds in cash, hire less 
productive but more loyal individuals -- perhaps relatives -- to make cheating safer, and so on.) If perfect compliance could be achieved through greater enforcement, these resources inefficiently expended by individuals in sector B would be saved. For a moderate increase in enforcement, however, the story is more complicated. When enforcement is very light, cheating might be easy and, therefore, cheap. When enforcement is increased but still not wholly effective, individuals may devote more resources to hiding income. This increase in evasion mitigates any direct equity or efficiency benefits of the greater enforcement effort and increases the resources (inefficiently) devoted to hiding income. Once such effects were measured, one could modify the analysis accordingly, allowing one to determine whether an enforcement plan increased social welfare. Comments on the Analysis

In the present context, one would not always expect behavioral responses fully to substitute inefficiency effects for inequity. Suppose, for example, that some individuals work in sector B because they are more productive as entrepreneurs in B than as employees in $A$. (One reason is that their skills are more useful in industry $\mathrm{B}$; another is that they have a personality that makes them a bad employee but a good entrepreneur.) Further, suppose that some of these individuals are honest; they report all income despite the ease of evasion. In the distorted equilibrium, their earnings are depressed by those who flock into sector B to take advantage of the low de facto taxes, but they continue to pay the full stated rate. As a result, they are worse off than those in sector B who are dishonest. Moreover, they are worse off than employees in A who, unlike themselves, receive higher before-tax wages to compensate for the fact that they pay taxes on all of their income. Thus, there is inequity with respect to these honest individuals, so a realistic account will involve both equity and efficiency effects. (This story is not far-fetched: the tax gap in many such sectors exceeds 50 percent. One possibility is that all individuals are 
cheating to the same extent. Another is that opportunities and temperaments vary greatly; some may be paying 100 percent and many others close to 0 percent.)

It also should be noted that tax evasion has a feedback effect on optimal tax rates. If different rates could be applied to these two sectors, a higher tax might be imposed on the sector with evasion: the higher tax would offset the underpayments by workers in the sector with evasion, which would improve equity (to the extent there is not full adjustment due to behavioral responses) and efficiency (by reducing the incentive for resources to flow excessively into the de facto undertaxed sector). One problem with this approach is that, as the tax rate in the sector with evasion is increased, individuals will evade more. This response reduces the direct benefits from the rate increase and raises the resource cost from evasion activity.

\section{CONCLUSION}

This article has examined a variety of imperfections in tax administration. All of the problems studied here involve a similar trade-off: rules that more accurately measure income, more accurate administration of such rules, and greater enforcement to improve compliance all typically raise aggregate administrative costs, whether compliance costs borne by taxpayers or enforcement costs borne by the government.

The administratively cheaper approach primarily involves costs of mismeasurement. To the extent such mismeasurement is not offset by behavioral responses, the resulting social cost involves inequity: some taxpayers pay more and others less than is warranted. It was suggested that the only reasonable way to measure these equity costs is by reference to a social welfare function, embodying the distributive objectives from which the tax base and rate structure were derived.

Often, behavioral responses will reduce or eliminate the resulting inequity, substituting 
inefficiency instead. This inefficiency arises because imperfect administration involves tax rates that de facto differ across sectors of the economy. Thus, the distortion is of a type that is familiar to tax policy analysts, so the problem can be analyzed in the customary manner.

For decades, many reformers have called for simplification, ranging from elimination of particular deductions to wholesale restructuring of our tax system. Others have noted the large tax compliance gap and advocated proposals ranging from greater IRS enforcement budgets to substitution of easier-to-administer taxes. What has been lacking in much of the debate, however, is a conceptual framework for assessing which reforms would increase social welfare. This article, hopefully, will help fill that void. ${ }^{22}$

The present investigation is, of course, only a beginning. The framework is rather simple whereas the range of problems and issues concerning tax complexity and enforcement are -- for lack of a better term -- complex. Moreover, a conceptual framework is of little use without empirical evidence. ${ }^{23}$ The demands in the present context are substantial. Fortunately, some work has already been done. In addition, with a more concrete analytical structure in hand, it should be clearer what information is most important to collect. 


\section{REFERENCES}

Alm, James. "The Welfare Cost of the Underground Economy." Economic Inquiry 23 (1985): 243-63.

Alm, James. "What is an 'Optimal' Tax System?" National Tax Journal (forthcoming 1996).

Alm, James, Isabel Sanchez, and Ana de Juan. "Economic and Noneconomic Factors in Tax Compliance." Kyklos 48 (1995): 3-18.

Arthur D. Little. Development of Methodology for Estimating the Taxpayer Paperwork Burden, Final Report to the Department of the Treasury. Washington, D.C.: Internal Revenue Service, 1988.

Bittker, Boris I. "Equity, Efficiency, and Income Tax Theory: Do Misallocations Drive Out Inequities?" San Diego Law Review 16 (1979): 735-48.

Blumenthal, Marsha, and Joel Slemrod. "The Compliance Cost of the U.S. Individual Income Tax System: A Second Look after Tax Reform." National Tox Journal 45 (1992): 185-202.

Bradford, David. Untangling the Income Tax. Cambridge: Harvard University Press, 1986.

Kaplow, Louis. "Horizontal Equity: Measures in Search of a Principle." National Tax Journal 42 (1989): 139-54.

Kaplow, Louis. "Optimal Taxation with Costly Enforcement and Evasion." Journal of Public Economics 43 (1990): 221-36.

Kaplow, Louis. "The Standard Deduction and Floors in the Income Tax." Tax Law Review (1994).

Kaplow, Louis. "A Fundamental Objection to Tax Equity Norms: A Call for Utilitarianism." National Tox Journal (forthcoming 1995).

Mayshar, Joram. "Taxation with Costly Administration." Scandinavian Journal of Economics 93 (1991): 75-88.

Mirrlees, J.A. “Taxing Uncertain Incomes." Oxford Economic Papers 42 (1990): 34-45.

Slemrod, Joel B. "The Simplification Potential of Alternatives to the Income Tax." Tax Notes (February 27, 1995): 1331-38.

Slemrod, Joel B., and Shlomo Yitzhaki. "The Optimal Size of a Tax Collection Agency." 
Scandinavian Journal of Economics 89 (1987): 183-92.

Slemrod, Joel B., and Shlomo Yitzhaki. "Analyzing the Standard Deduction as a Presumptive Tax." International Tax and Public Finance 1 (1994): 25-34.

Slemrod, Joel B., and Shlomo Yitzhaki. "The Social Cost of Taxation and the Marginal Cost of Funds." IMF/FAD Working Paper (1995).

U.S. General Accounting Office. Taxpayer Compliance: Reducing the Income Tax Gap. GAO/T-GGD-95-176, Washington, D.C.: June, 1995.

Yitzhaki, Shlomo. "A Note on Optimal Taxation and Administrative Costs." American Economic Review 69 (1979): 475-80. 


\section{ENDNOTES}

I am grateful for comments from James Alm, Reuven Avi-Yonah, Diane Ring, Steven Shavell, Joel Slemrod, and Alvin Warren, research assistance from Travis Pearson, and support from the John M. Olin Center for Law, Economics, and Business at Harvard Law School. The symposium piece by Alm (1996) is in many respects complementary to this investigation.

1. This may be expressed by stating the individual's budget constraint as

$$
C=w L-T(w L) .
$$

The term $w$ refers to the wage rate, and $T(w L)$ indicates the amount of income tax owed on income of wL. The present formulation abstracts from savings, taxation of capital income, and numerous other complications. Incorporating additional dimensions would make the problem more difficult but would not alter its essential character.

2. Information about individuals' trade-off between income and leisure is derived from empirical studies of labor supply, which typically assess the responsiveness of hours worked or labor market participation to changes in after-tax wage rates. Information about how the marginal utility of income depends on income levels can be derived from studies of behavior under uncertainty. For example, the amount that individuals are willing to pay to insure against losses of income indicates how much they value avoiding a low-income situation.

3. This characterization of the primary sources of compliance costs is borne out by the empirical work on the subject. See Arthur D. Little (1988), Blumenthal and Slemrod (1992).

4. An extreme but important example of sacrificing accurate measurement for the sake of reducing compliance and administrative costs involves the use of presumptive taxation -- e.g., estimating restaurant sales from the square feet occupied by the restaurant or measuring property values by counting the number of windows. Within the income tax, standardized depreciation schedules and the use of standard deductions and floors may serve a similar purpose. See Kaplow (1994), Slemrod and Yitzhaki (1994).

5. If it did not, the adverse incentive effects of redistributive taxation would not be offset by any distributive benefit, so no income -- or other "ability-to-pay" taxation -- would be justified in the first place.

6. To simplify the exposition, I assume that the government's revenue requirement is held constant, so that the taxpayer's reduced obligation when the deduction is allowed as well as the government's additional administrative costs must be made up through higher taxes.

Alternatively, other government expenditures would have to be reduced, substituting a different welfare cost. (If government expenditures are optimized, the marginal social cost of tax revenue will just equal the marginal social benefit of expenditures, so that the social welfare cost will be the same if marginal adjustments to restore budget balance are made by tax increases or program cuts.) 
7. Note that even a purely proportional or moderately "regressive" tax is massively redistributive by comparison to a head tax. One cannot speak as though we have not made a substantial decision involving redistribution just because there is not that much net "progressivity" -graduation of effective tax rates -- in the current tax system.

8. Under a utilitarian social welfare function, this result is due to the decreasing marginal utility of income. For more egalitarian social welfare functions, the weight of this concern would be greater. See Mirrlees (1990).

9. In the extreme, the problem would, however, vanish: if all taxpayers' incomes were overstated by the same $\$ 5,000$, one could simply adjust the tax brackets by that amount -- say, by giving everyone an additional $\$ 5,000$ exemption -- and there would be no problem at all. Thus, the problem does involve relative mismeasurement, but not particularly mismeasurement among individuals of equal income. It also does not involve rank reversals in the income distribution. If there were no individuals within $\$ 5,000$ of the large group that was mis-taxed, the equity cost described in the text would be unaffected. For further discussion suggesting that horizontal equity and concerns about rank reversals do not constitute an independent norm in the present context, see Kaplow $(1989,1995)$.

10. This latter point is relevant to the appropriate tax treatment of the compliance costs themselves (e.g., whether they should be deductible).

11. Such tax breaks might induce some individuals to feign blindness, the type of problem addressed in the later section on enforcement.

12. This possibility has been emphasized by Bittker (1979) and Bradford (1986), among others.

13. In long-run equilibrium, one would generally expect full adjustment in many instances. Note that it is not necessary that all individuals be able to respond to the economic incentives. Assume, for example, that there are 100 workers, that in the efficient (perfect income measurement) equilibrium there are 50 in each sector, and that in the distorted equilibrium (when a deduction in one sector is not permitted because of compliance costs) there are 40 workers in sector A and 60 in B. To reach the distorted equilibrium, it takes only 10 of the 50 who would otherwise have gone into A to work in B instead. Thus, even if most could (would) not move, it is entirely possible that the full adjustment just described would occur. Those who were "stuck" in A would still benefit from the higher before-tax wage that prevails in equilibrium, so there would not be any equity effect.

If adjustment between sectors is partial, workers' effective tax (and thus wage) rates will differ. This difference will tend to increase the distortion in labor effort because distortion tends to rise disproportionately with tax rates. (That is, the increase in distortion with respect to those facing a higher effective tax rate will tend to be more than the decrease in distortion with respect to those facing a lower effective tax rate.)

14. Yitzhaki (1979) has performed such an analysis in the case of commodity taxation: omitting commodities from the tax base creates distortion; including them involves greater administrative costs. 
15. It is possible that in some instances more intensive auditing would reduce costs, because taxpayers would be deterred from incurring additional costs to avoid taxation, as is discussed in the following section on enforcement. In such instances, a more accurate system would be unambiguously desirable.

16. I will emphasize enforcement efforts that tend to affect most directly taxpayers' economic incentives to comply. Many researchers emphasize sociological and psychological factors as well, but these factors are not unrelated. For example, if there are low incentives for compliance, a large number of taxpayers might cheat; once cheating is sufficiently widespread, more honest taxpayers may lose some of their inhibitions to evasion, magnifying these effects. For a discussion of a range of factors affecting compliance and experimental evidence on their interaction, see Alm, Sanchez, and de Juan (1995).

17. See, e.g., Kaplow (1990), Mayshar (1991), Slemrod and Yitzhaki (1987).

18. Another alternative is to impose requirements on the private sector, with the result that most of the administrative costs will not be reflected in the government's budget. These are, of course, real resource costs of greater enforcement regardless of who must foot the bill.

19. As another provocative example, suppose that all taxpayers paid half of what they owed -perhaps each is able costlessly to hide half of income, whatever its level. One could spend a massive amount to uncover the hidden income. Alternatively, one could simply double the tax rate; each individual then pays twice the proper rate on half the base, for the same total tax bill. All the enforcement resources required to find and demonstrate the hidden income would be saved.

20. As explained in note 6 , one could view the resulting problem as one of reduced government expenditures, leading to similar analysis.

21. In addition to the previously noted distortions between industries and in the use of inputs, there is the possibility that the organizational form may be inefficient, as when individuals who would function better as employees instead become entrepreneurs. (The inefficiency may involve the bearing of risk, loss of economies of scale, problems of lack of managerial ability, and so on.)

22. See also prior work by Kaplow (1990) and Mayshar (1991) and a range of work by Slemrod and Yitzhaki, in particular their recent paper (1995) which integrates administrative issues in the context of assessing reforms involving marginal changes in tax rates.

23. It was also emphasized that one must choose a social welfare function, which necessarily involves value judgments. As noted, one approach is to infer such judgments from existing institutions (as by determining what social welfare function would generate a degree of redistribution close to that actually observed). On the more purely normative side, I believe that the argument for a utilitarian norm is stronger than is generally recognized. See Kaplow (1995). 